\title{
Half a degree warming might cause doubled economic loss and intensified affected population of flood in China
}

\author{
Lulu Liu ${ }^{1,2}$, Jiangbo $\mathrm{Gao}^{1,2}$, Shaohong $\mathrm{Wu}^{1.2 .3}$ \\ ${ }^{1}$ Institute of Geographic Sciences and Natural Resources Research, CAS, Beijing 100101, China \\ $5 \quad{ }^{2}$ Key Laboratory of Land Surface Pattern and Simulation, CAS, Beijing 100101, China \\ ${ }^{3}$ University of Chinese Academy of Sciences, Beijing 100049, China
}

Correspondence to: Jiangbo Gao ( gaojiangbo@igsnrr.ac.cn )

Abstract. Based on future scenario data and an improved quantitative assessment model of natural disaster risk, in this paper,

10 we analyze the response of the characteristics of flooding events in China to $1.5^{\circ} \mathrm{C}$ and $2^{\circ} \mathrm{C}$ of global warming, quantitatively assess social and economic risks of the floods, and determine the integrated risk levels. The results indicate that for the $\mathrm{RCP} 4.5$ and RCP8.5 scenarios, the hazard and distribution area of the floods increase with increasing temperature and the influence range of floods in different levels expands more rapidly under RCP4.5 scenario. The floods mainly affect the social economy in the regions with lower altitudes and smaller slopes in eastern China. With intensification of temperature rise, the affected

15 population and the direct economic losses would be aggravated. For $2^{\circ} \mathrm{C}$ of global warming, under RCP8.5 scenario, affected population by floods would increase by 2 million and the economic risk would nearly double compared with $1.5^{\circ} \mathrm{C}$ of global warming. The economic risk under RCP4.5 scenario would even reach three times that for $1.5^{\circ} \mathrm{C}$ of global warming, but its proportion to GDP is lower than that of RCP8.5 scenario. Under both scenarios, the ranges of the medium-high flood risk zones would gradually expand westward and northward.

\section{Introduction}

In recent decades, changes in climate have caused impacts on natural and human systems on all continents and across the oceans (IPCC, 2012; IPCC, 2014). At the global and regional scales, climate-related hazards have caused enormous damage (Kundzewicz et al., 2014; Johnson et al., 2016; Luo et al., 2018; Paprotny et al., 2018), resulting in a significant increase in economic losses (Parmesan and Yohe, 2003; Patz et al., 2005). In 1998-2017, countries influenced by climate-related disasters reported direct economic losses of $\$ 2.245$ trillion USD, of which floods were the most frequent type of disaster, making up $43 \%$ of all recorded events (Swiss Re Group, 2017; UNISDR and CRED, 2018). Over the last 20 years, China has suffered the second largest loss due to the frequent occurrence and serious impacts of climate-related hazards (Ding et al., 2006; Huang et al., 2007; UNISDR and CRED, 2018). Among all of the meteorological and hydrological disasters, floods are characterized by sudden and frequent occurrence, and the direct economic losses caused by these events account for the largest proportion of the total economic losses of climate-related hazards (Writing Committee for Third National Assessment Report on Climate 
Change, 2015). Since 2004, the mean annual direct economic loss due to floods in China has exceeded $\$ 20$ billion USD, and the affected population has exceeded 100 million with more than 1000 deaths (Song, 2016; Feng et al., 2018).

In order to reduce the risks and impacts of climate change and strengthen the global response to the threat of climate change, the Paris Agreement committed to controlling the increase in the global mean surface temperature (GMST) to "well below

$352{ }^{\circ} \mathrm{C}$ above preindustrial levels and pursuing efforts to limit the temperature increase to $1.5^{\circ} \mathrm{C}$ above pre-industrial levels" (UNFCCC, 2015). The Intergovernmental Panel on Climate Change (IPCC) Special Report on the impacts of $1.5^{\circ} \mathrm{C}$ of global warming states that $1.5^{\circ} \mathrm{C}$ of global warming can effectively reduce the risk of climate change and avoid the occurrence of irreversible risks and losses (IPCC, 2018). Globally, Climate change is expected to accelerate the global hydrologic cycle (Held and Soden, 2006; Huntington, 2006; Durack et al., 2012; Trenberth et al., 2014), and increase the frequency and intensity

40 of extreme rainfall events and severe storm surges (Wahl et al., 2015; King et al., 2017a, b; Rahmstorf, 2017; Kharin et al., 2018; Li et al., 2018b; Zhang et al., 2018). Upper middle income countries will suffer the largest increase in flood damage, and China will suffer the most serious direct economic losses (Jevrejeva et al., 2018; Willner et al., 2018). The regions with high flood risk levels are mainly located in southeastern China (Xu et al., 2014). The frequency of events similar to the extreme floods during the summer of 2010 will increase by 2 and 3 times for global warming of $1.5^{\circ} \mathrm{C}$ and $2^{\circ} \mathrm{C}$, respectively (Lin et al., 2018). Society economic exposure will mainly increase in the economically developed regions in the east (Li et al., 2018a).

Previous studies have paid more attention to the possibility of floods (Hirabayashi et al., 2013; Lin et al., 2018) and have determined the socioeconomic risks of floods using the simple superposition of risk causing factors and exposures ( $\mathrm{Li}$ et al., 2018). Few studies have been conducted on the quantitative assessment of flood risk considering the vulnerability of risk bearing bodies (Alfieri et al., 2015; Wobus et al., 2017). However, the connotation of risk should include risk causing factors,

50 disaster-pregnant environment and risk bearing bodies. The adverse effects of floods depend not only on the extreme events themselves, but also on the exposure and vulnerability of risk bearing bodies (IPCC, 2012). At present, it is urgent to quantitatively assess the social and economic risks of floods and their trends under different global warming targets by clarifying the magnitude and frequency of floods, the vulnerability, and the social and economic exposure in order to improve the level of risk analysis, reduce losses caused by floods, and provide a basis for addressing climate change and preventing natural disasters under different global warming targets.

Based on the quantitative evaluation theory for climate change risk and the magnitude and frequency of pluvial floods, in this study, we calculated the hazards of floods in China for $1.5^{\circ} \mathrm{C}$ and $2.0^{\circ} \mathrm{C}$ of global warming using the bias-corrected daily output results from the global climate models. By combining social and economic exposure and the latest vulnerability to different levels of floods, social and economic risks of the floods were quantitatively assessed to provide support for establishing disaster management systems, carrying out effective risk management, ensuring sustainable development of the national economy and society, and implementing adaptation and mitigation strategies. 


\section{Materials and Methods}

\subsection{Data sources}

We selected 5 Global Climate Models (HadGEM2-ES, GFDL-ESM2M, IPSL-CM5A-LR, MIROC-ESMCHEM, and

65 NorESM1-M) from The Inter-Sectoral Impact Model Inter-Comparison Project (ISI-MIP) driven by multiple Representative Concentration Pathways (RCP4.5 and RCP8.5 were selected in this study) scenarios (Warszawski et al., 2014). The climate projections were bias-corrected using methodology of modification of the transfer function based on the water and global change (WATCH) forcing data (WFD) (Weedon et al., 2011; Hempel et al., 2013) with a spatial resolution of $0.5^{\circ} \times 0.5^{\circ}$ and a daily step from 1950 to 2099 . The simulation results satisfactorily represent the ranges of climate change and the corresponding 70 impacts of the other CMIP5 models (Huang et al., 2017). Thus, they were used to calculate the magnitude and frequency of floods and classify their hazards.

Social and economic data derived from the Shared Socioeconomic Pathways (SSPs) scenarios (O’Neill et al., 2014) and from downscaling the scenario datasets, including the population and GDP, were used by the National Institute for Environmental Studies, Japan to create a simulation based on the SSP Database of the International Institute for Applied

75 Systems Analysis (IIASA). The data intervals were every ten years from 1980 to 2100 , and the spatial resolution was $0.5^{\circ} \times 0.5^{\circ}$ (Murakami and Yamagata, 2016). The SSP1 and SSP3 scenarios were selected, which corresponding to the RCP4.5 and RCP8.5 scenarios, respectively (https://tntcat.iiasa.ac.at/SspDb/dsd?Action=htmlpage\&page=about). The data were used to assess the social and economic risk of the floods as the exposure of the risk bearing bodies.

\subsection{Analysis methods}

\section{$80 \quad$ 2.2.1 Determination of the different temperature increase periods}

We selected global warming targets of $1.5^{\circ} \mathrm{C}$ and $2^{\circ} \mathrm{C}$ based on the objectives of the Paris Agreement. Previous work of scholars found that the GMST is projected to reach $1.5^{\circ} \mathrm{C}$ by around 2030 for both RCPs whereas the $2^{\circ} \mathrm{C}$ target is reached by 2040 for RCP8.5 and by 2050 for RCP4.5 (Karmalkar and Bradley, 2017; Nikulin et al., 2018; Su et al., 2018; Gao et al., 2020). We chose the 30 years of the threshold year as the last year as the warming period of $1.5^{\circ} \mathrm{C}\left(2.0^{\circ} \mathrm{C}\right)$.

\section{$85 \quad$ 2.2.2 Quantitative assessment model for natural disaster risk}

The quantitative assessment model for natural disaster risk consists of three components: the destructive power of the natural disasters or the damage standard of the risk bearing bodies (D), exposure of the risk bearing bodies (E), and the probability of disaster or disaster-pregnant environments (P) (Wu et al., 2018a), combined with the most common approach used "equal weight" method (Papathoma-Köhle et al., 2019), the formula is as follows:

$$
R=D \times E \times P
$$


Bates et al. (2008) pointed out that floods are affected by a variety of climatic and non-climatic processes. Precipitation is the most important climatic process. Flood disasters in China are mostly caused by intense precipitation, and the intensity and losses of the floods are closely related to the corresponding precipitation. Therefore, the amount of precipitation can be used to classify the intensity of floods (Zhai et al., 1999; Gong and Wang, 2000; Zhai et al., 2005; Ma et al., 2018). From the perspective of historical flood disasters, the maximum accumulated 3-day precipitation has an important impact on the occurrence of floods during the continuous precipitation process. Generally, mild, moderate, and severe floods correspond to maximum accumulated 3-day precipitation values of 30 (35) - $150 \mathrm{~mm}, 150$ - $250 \mathrm{~mm}$ and $\geq 250 \mathrm{~mm}$, respectively (Li et al., 2012). Among non-climatic processes, altitude and slope have the greatest impact on the formation and development of floods, so they can be used as environmental correction parameters for the underlying surface (Zhou et al., 2000; Thompson and Clayton, 2002; Li et al., 2012).

Based on the above theories, the probability of floods can be expressed as:

$$
P=F \times I
$$

where $\mathrm{P}$ is the probability or hazard of flood, $\mathrm{F}$ indicates the possibility of intense precipitation, and I is the environmental correction parameter for the underlying surface.

105 Correspondingly, the quantitative assessment model of the social and economic risks of pluvial floods can be expressed as follows:

$$
R=(D \times E) \times(F \times I)
$$

where $\mathrm{R}$ is the social and economic risk of the floods, $\mathrm{D}$ is the destructive power of different magnitudes of floods, and $\mathrm{E}$ is the exposure of the risk bearing bodies.

Therefore, the steps of the social and economic risk assessment of pluvial floods in China are as follows:

The maximum accumulated 3-day precipitation values of 30 (35) -150 mm, $150-250 \mathrm{~mm}$ and $\geq 250 \mathrm{~mm}$ were taken as the maximum occurrence of mild, moderate, and severe floods. These values were converted into a probability (probability $=$ frequency/time period $\times 100 \%$, set to 1 if the probability is greater than $100 \%$ ). Furthermore, considering the heterogeneity of the regional geographical environment, the environmental correction parameter of the underlying surface, which is based on the altitude and slope, was used to correct this probability. Thus, the hazard of flooding was obtained;

Flood disasters can have serious impacts on the economy and society. GDP and population were selected as the exposure of the economy and society. For the destructive power of floods, a quantitative relationship was established between the different magnitudes of the floods and the loss rates of GDP and population according to the classification criterion of the maximum accumulated 3-day precipitation based on statistical data for 1001 flood disasters from 1990 to 2008 in China, which was obtained from Li et al. (2012);

The exposures of the economy and society were obtained from SSPs data given in the data sources section;

The social and economic risks of floods were quantitatively evaluated based on the hazards and destructive power of floods and the exposures of risk bearing bodies; 
Finally, the integrated risk of floods was obtained using the superposition analysis method and was graded using the multiple of the standard deviation method.

\section{Results}

\subsection{Hazards of Floods}

When the GMST increases by $1.5^{\circ} \mathrm{C}$, under RCP 8.5 scenario, the distribution areas of severe, moderate, and mild floods would be about 1.92, 3.90, and 6.92 million km2, respectively. Generally speaking, severe floods would be mainly concentrated in

130 South China, East China, the southeastern part of the Qinghai-Tibet Plateau, the southwestern part of Southwest China, and the southern part of Northeast China. Moderate floods would be distributed in South China, East China, Central China, the central and southern parts of Northeast China, the southern part of North China, and the southern part of Southwest China. Mild floods would occur in most parts of the country except on the Qinghai-Tibet Plateau and in the Tarim Basin. Under RCP4.5 scenario, the hazard of severe floods in Central China would be higher, and the distribution areas of severe, moderate, and mild floods would be larger than those for RCP8.5 scenario (Fig. 1; Figure 2a, c, e; Fig. S1a, c, e).

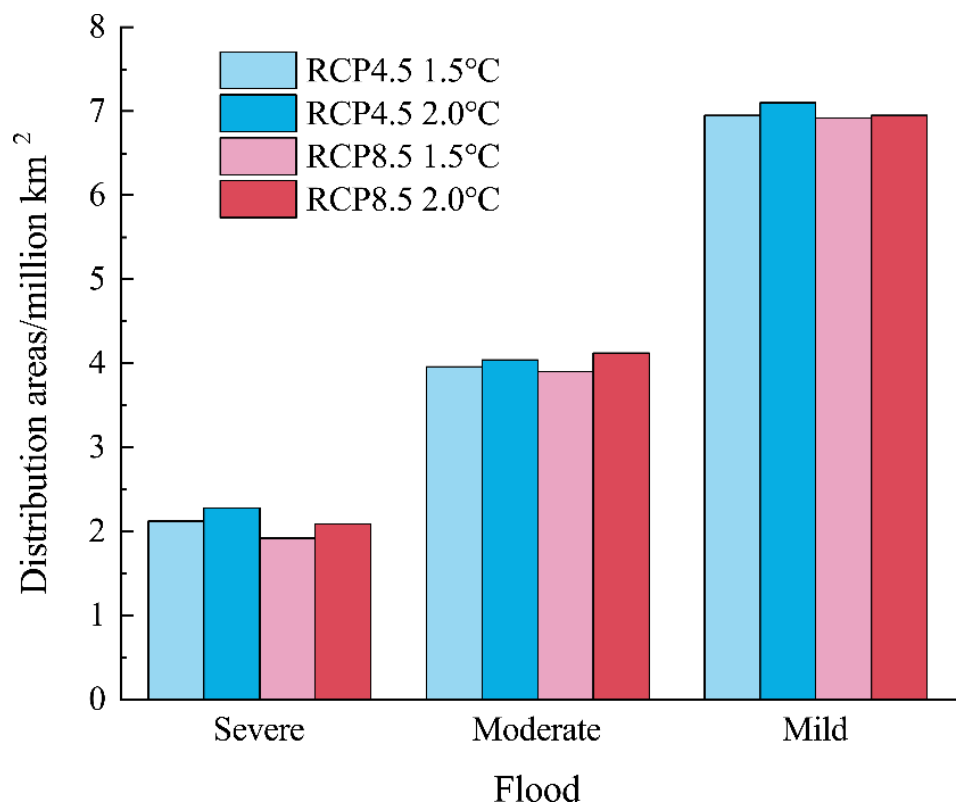

Figure 1. Distribution areas of floods of different levels for $1.5^{\circ} \mathrm{C}$ and $2^{\circ} \mathrm{C}$ of global warming (units: million $\mathrm{km}^{2}$ )

When the GMST increases by $2^{\circ} \mathrm{C}$, under RCP8.5 scenario, the distribution areas of severe and moderate floods would 140 increase to approximately 2.09 and 4.12 million $\mathrm{km} 2$, respectively. The hazards of severe and moderate floods would increase in the eastern part of Central China. The distribution area and hazard of mild floods would be basically the same as those for $1.5^{\circ} \mathrm{C}$ of global warming. Under RCP4.5 scenario, the distribution areas of floods of different levels would increase, the hazard 
of severe floods in the central and northern parts of East China would increase, and the moderate and mild flood zones would expand westward (Fig. 1; Fig. 2b, d, f; Fig. S1b, d, f).
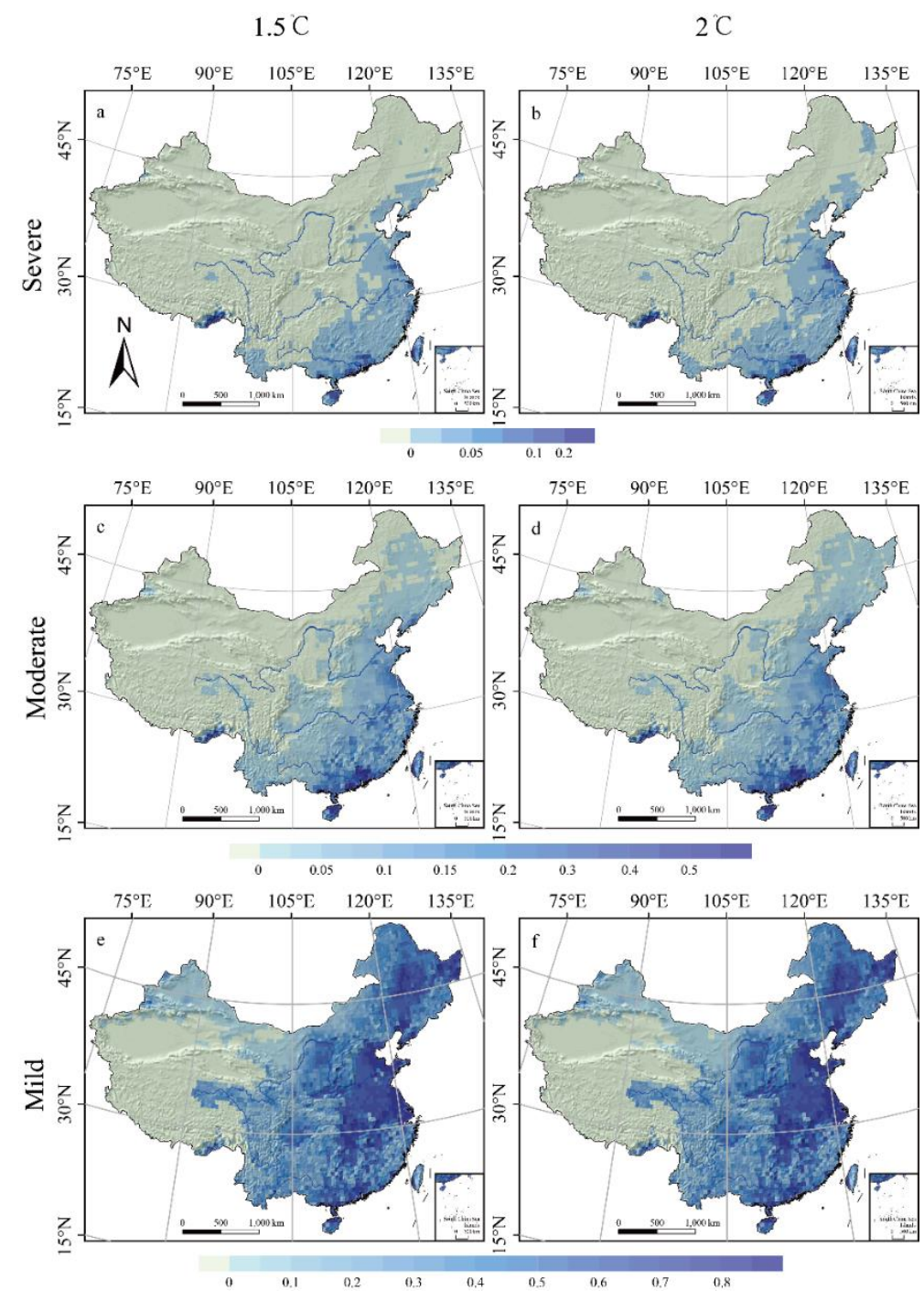

Figure 2. Spatial patterns of the hazards of floods of different levels for $1.5^{\circ} \mathrm{C}$ and $2^{\circ} \mathrm{C}$ of global warming under RCP8.5 scenario (a-b. severe floods; c-d. moderate floods; e-f. mild floods; a, c, e. $1.5^{\circ} \mathrm{C}$ of warming; b, d, f. $2^{\circ} \mathrm{C}$ of warming)

Compared with global warming of $1.5^{\circ} \mathrm{C}$, severe flood hazard index would increase significantly for global warming of $2^{\circ} \mathrm{C}$ under RCP4.5 and RCP8.5 scenarios, and the hazard index in some areas would double; the hazard index would decrease in coastal East China, Central China and South China under RCP4.5 scenario; in contrast, under RCP8.5 scenario, the hazard index would only decrease in southern Central China and southern Yunnan Province, and would increase significantly in South China (Fig. S2a, b). Moderate flood hazard index would double in the North China Plain and the Yunnan-Guizhou Plateau (eastern Northeast China) under RCP4.5 (RCP8.5) scenario, and the hazard index would decrease in the Northeast Plain, Loess 
155 Plateau and southern Central China under both scenarios (Fig. S2c, d). The changes of mild hazard index would be mainly concentrated in the Northwest China, with an increase in the eastern and a decrease in the western under RCP4.5 and RCP8.5 scenarios (Fig. S2e, f).

\subsection{Flood risks for the population and economy}

Floods have serious impacts and cause damage to the social economy, food production, natural ecosystem, and infrastructure.

160 In this study, the population and economy were selected as the risk bearing bodies to quantitatively assess the risks of floods in the future.

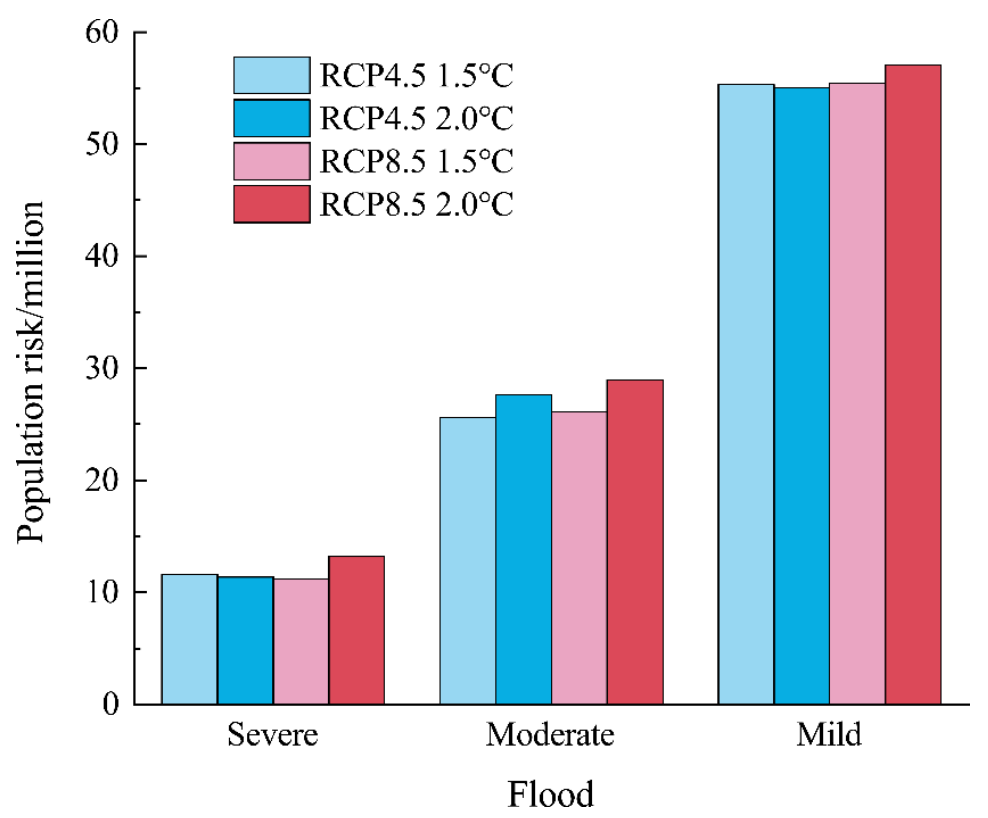

Figure 3. Population risks of floods of different levels for $1.5^{\circ} \mathrm{C}$ and $2^{\circ} \mathrm{C}$ of global warming (units: million)

For $1.5^{\circ} \mathrm{C}$ of global warming, under RCP8.5 scenario, severe floods would affect more than 11 million people, and the direct economic losses would be about $\$ 33$ billion USD. These floods would mainly occur in South China, the central and northern parts of East China, the southern part of Central China, the southern part of Northeast China, and southern Tibet. Moderate floods would affect about 26 million people, the direct economic losses would be about $\$ 42$ billion USD, and would mainly occur in the Bohai Rim, the central and northern parts of East China, South China, Central China, the southern and eastern parts of Southwest China, and southern Tibet. The affected population and the direct economic losses of mild floods would be about

17055 million and $\$ 70$ billion USD, respectively, and the regions with high risk levels would mainly be distributed in the North China Plain, the Northeast Plain, the Middle-Lower Yangtze Plain, the Sichuan Basin, and the Pearl River Basin. The distribution of the population and economic risks under RCP4.5 scenario would be basically consistent with RCP8.5 scenario, but the scope would shift westward. The affected population and the direct economic loss in the southern part of the Yangtze 
River region would be greater than that for RCP8.5 scenario (Fig. 3; Fig. 4a, c, e; Fig. 5; Fig. 6a, c, e; Fig. S3a, c, e; Fig. S5a, $\mathrm{c}, \mathrm{e})$.
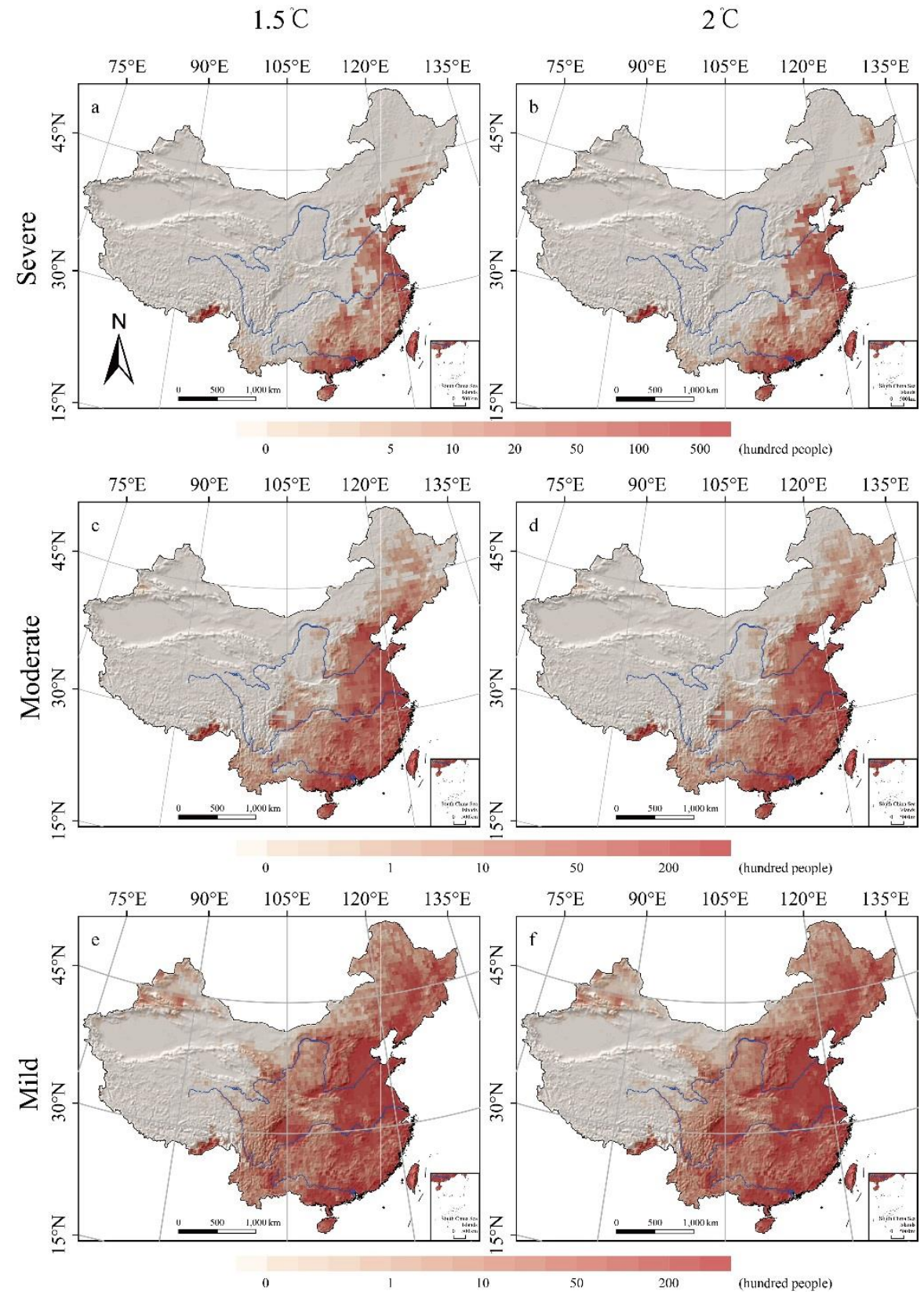

Figure 4. Spatial patterns of the population risks of floods of different levels for $1.5^{\circ} \mathrm{C}$ and $2^{\circ} \mathrm{C}$ of global warming under RCP8.5 scenario (a-b. severe floods; c-d. moderate floods; e-f. mild floods; a, c, e. $1.5^{\circ} \mathrm{C}$ of warming; b, d, f. $2^{\circ} \mathrm{C}$ of warming) 
For $2^{\circ} \mathrm{C}$ of global warming, under RCP8.5 scenario, compared with $1.5^{\circ} \mathrm{C}$ of global warming, the population affected by severe floods would increase by about 2 million, the direct economic loss would double, and the risk in Central China would increase. Moderate floods would affect nearly 29 million people, the direct economic loss would be close to \$78 billion USD, and the impact range would expand northward and westward. The population affected by mild floods would increase by more than 2 million, and the direct economic loss would nearly double, but the impact range would be basically the same as that for

$1851.5^{\circ} \mathrm{C}$ of global warming. Under RCP4.5 scenario, the population affected by floods of different levels would be lower, and the direct economic loss would be significantly higher. However, the proportion of GDP would be less than that for RCP8.5 scenario. The impact ranges of the two scenarios would be basically the same (Fig. 3; Fig. 4b, d, f; Fig. 5; Fig. 6b, d, f; Fig. S3b, d, f; Fig. S5b, d, f).

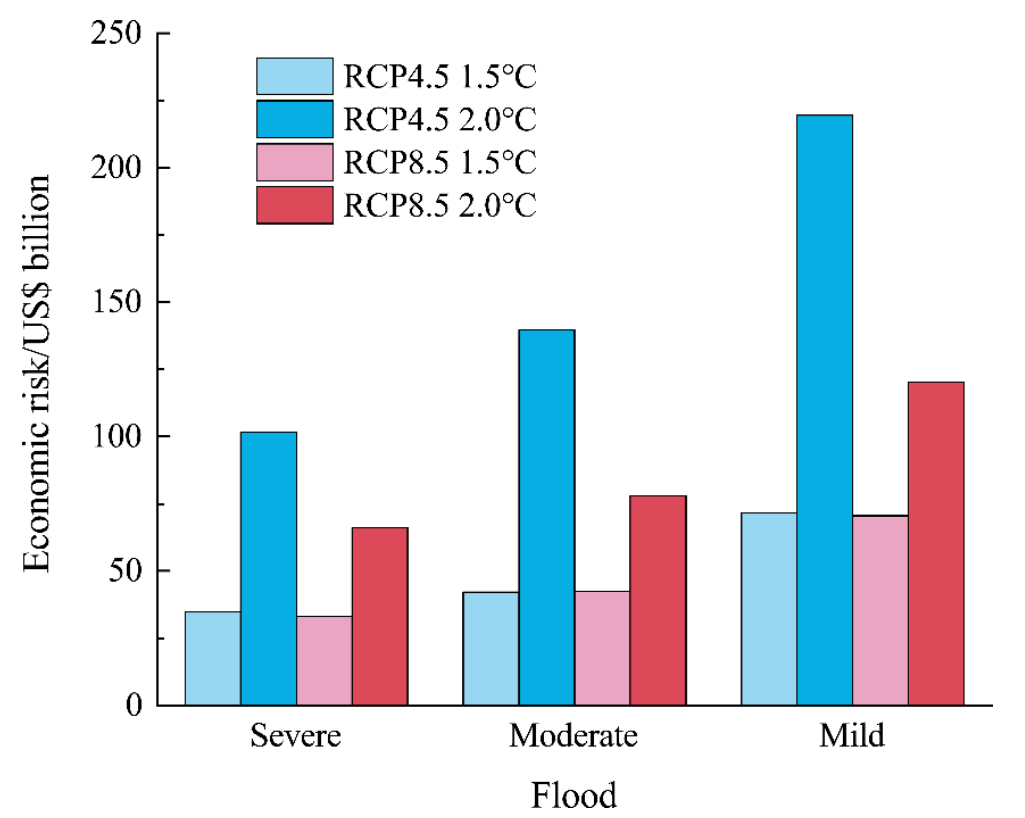

190 Figure 5. Economic risks of floods of different levels for $1.5^{\circ} \mathrm{C}$ and $2^{\circ} \mathrm{C}$ of global warming (units: US\$ billion)

Compared with global warming of $1.5^{\circ} \mathrm{C}$, population risks of severe floods under RCP8.5 scenario for global warming of $2^{\circ} \mathrm{C}$ would increase significantly in most of eastern China, except for southern Northeast China, southern Central China, southern Yunnan and Taiwan Province, and in some areas the risk would double; the population risks of severe floods under

195 RCP4.5 scenario would increase in southern Northeast China, East China and southern Southwest China, and would decrease in Central China and South China (Fig. S4a, b). The changes in population risks of moderate floods would be mainly distributed in eastern of the Heihe-Tengchong Line. The distribution patterns under both scenarios would be similar, and the areas of increased risk would be mainly concentrated in the North China Plain and the Yangtze River Basin (Fig. S4c, d). The change in population risks of mild floods to the eastern of the Heihe-Tengchong line would be small, while the change in the western 
https://doi.org/10.5194/nhess-2021-304

Preprint. Discussion started: 21 October 2021

(c) Author(s) 2021. CC BY 4.0 License.
Natural Hazards and Earth System Sciences

Discussions

200 of the Heihe-Tengchong line would be large, with the most significant increases mainly in northern North China, Northwest China and the Sanjiangyuan (Fig. S4e, f).
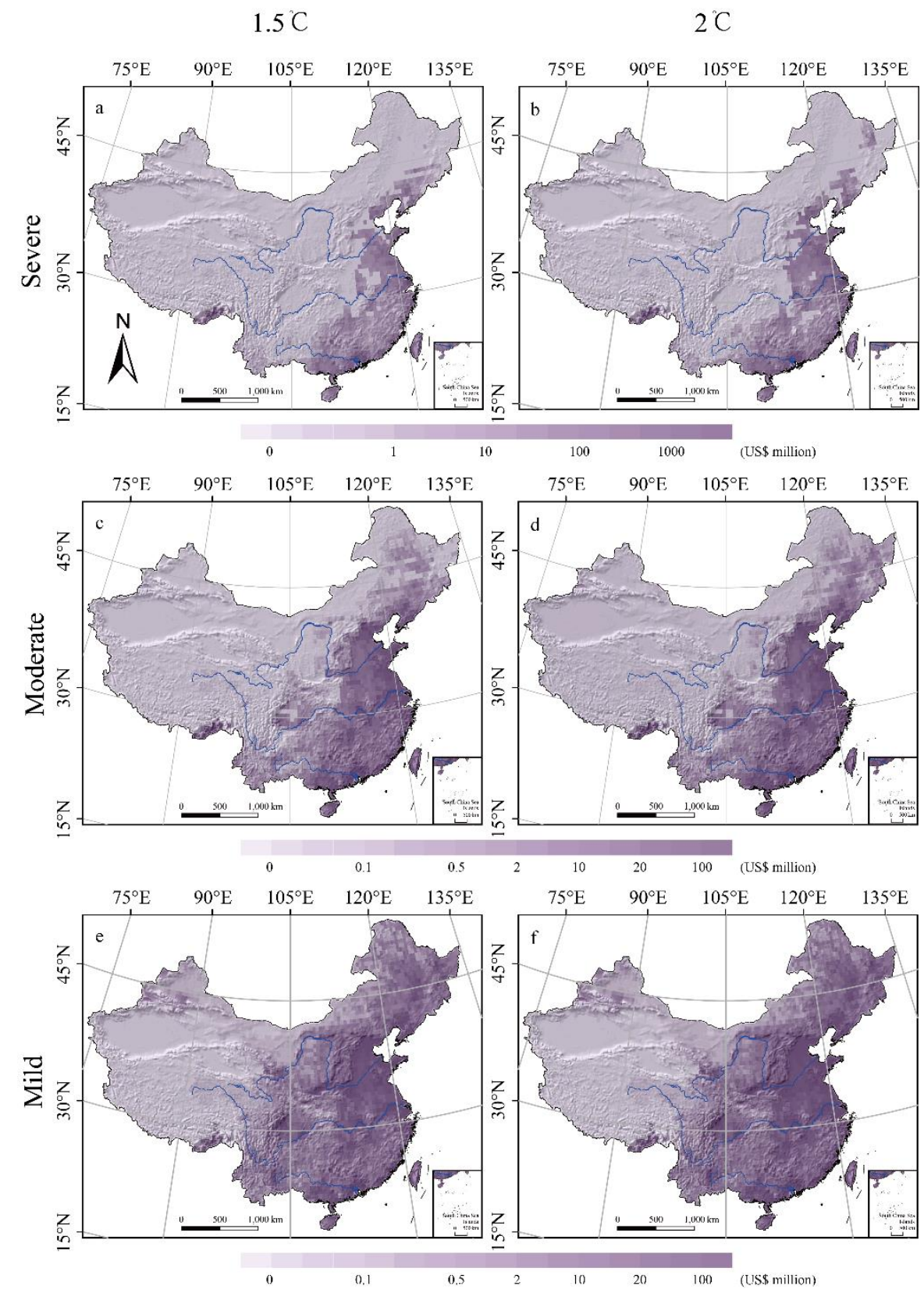

Figure 6. Spatial patterns of the economic risks of floods of different levels for $1.5^{\circ} \mathrm{C}$ and $2{ }^{\circ} \mathrm{C}$ of global warming under RCP8.5 scenario 205 (a-b. severe floods; c-d. moderate floods; e-f. mild floods; a, c, e. $1.5^{\circ} \mathrm{C}$ of warming; b, d, f. $2^{\circ} \mathrm{C}$ of warming) 
Compared with global warming of $1.5^{\circ} \mathrm{C}$, the economic risk of floods in different grades would be mainly increase under the effect of economic growth for global warming of $2^{\circ} \mathrm{C}$. The economic risks of severe floods under RCP4.5 and RCP8.5 scenarios would decrease in parts of Central China and would increase in most of eastern China, with the risk in the North China Plain would increase by more than 500\% (Fig. S6a, b). Under RCP8.5 scenario, the economic risks of moderate floods would decrease on both sides of the Heihe-Tengchong Line and would nearly double on the eastern side of the Line, with the risk increasing more than fivefold in the Northeast Plain and the Qinling Mountains. Under RCP4.5 scenario, the risks would decrease on both sides of the Heihe-Tengchong Line and eastern Northeast China. The risks in most areas on the eastern of the Line would increase by about 2 times, and the risks in the southern Southwest China would increase by more than 10 times (Fig. S6c, d). Under RCP8.5 scenario, the economic risks of mild floods would increase within 100\% in most parts of the country, and the

215 risk increase in the northern Northwest China would be more than twice. Under RCP4.5 scenario, the risks in most parts of the country would increase by more than $200 \%$, and the risk in the northern Northwest China and the Sanjiangyuan would increase by more than 10 times.

\subsection{Integrated risks of floods}

Based on the above quantitative assessment of the population and economic risks of floods, the standard deviation method was used to assess the integrated risks of floods.

For $1.5^{\circ} \mathrm{C}$ of global warming, the risk distributions under RCP4.5 and RCP8.5 scenarios would be generally consistent. The integrated risks of floods would occur in most parts of the country except on the Qinghai-Tibet Plateau and in the Tarim Basin. The high level risk regions would be mainly concentrated in East China, South China, Central China, the central and southern parts of Northeast China, the southeastern parts of North China, southern Tibet, and the eastern and western sides of the 225 Sichuan Basin. The medium level risk regions would be mainly distributed in Northeast China, the central part of North China, the eastern part of Northwest China, the central and western parts of Southwest China, and the Jiangnan region. The mediumhigh risk zones would account for $45 \%$ of the national total land area of China (Fig. 7a, c). 


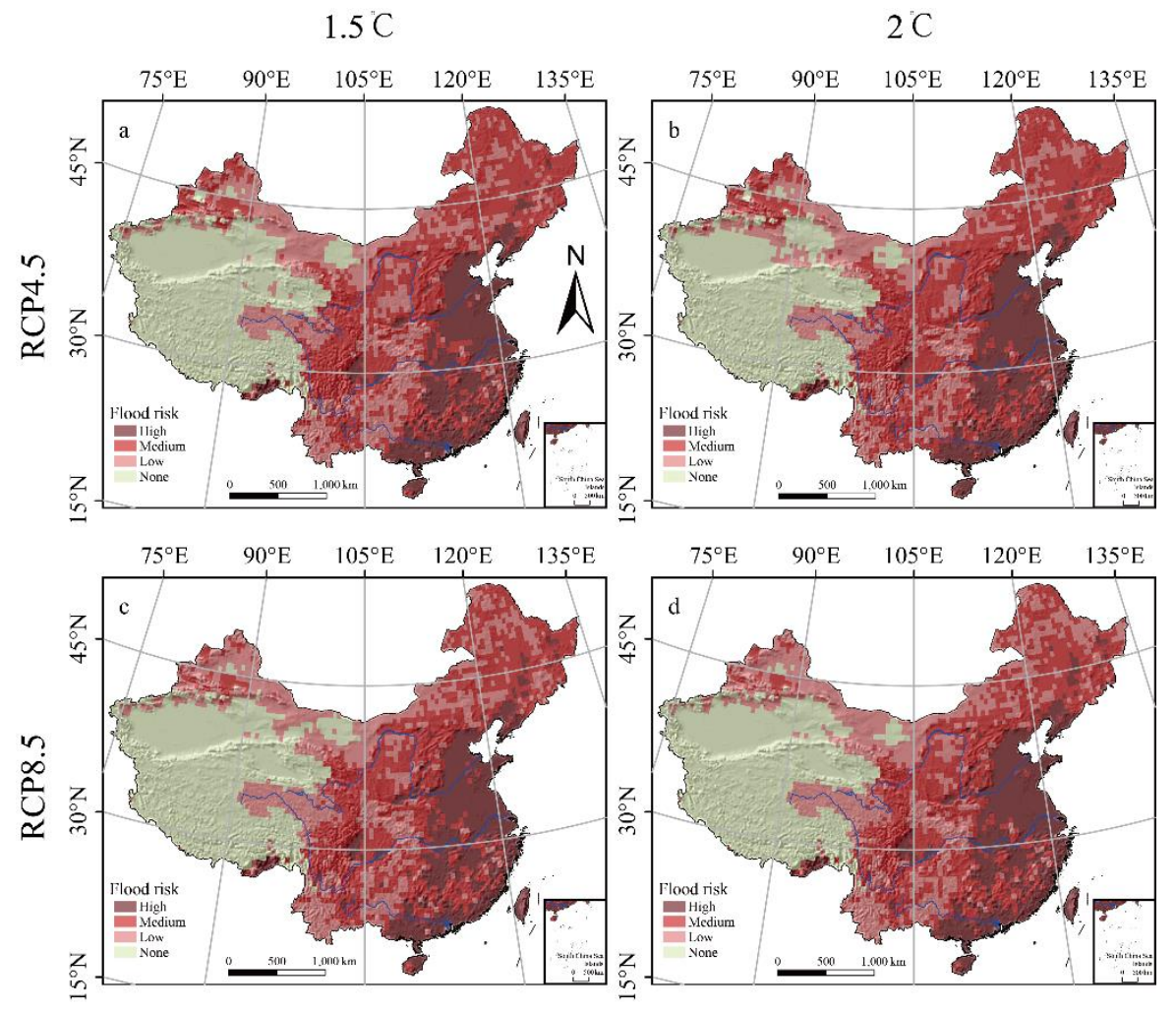

Figure 7. Spatial patterns of the integrated risks of floods for $1.5^{\circ} \mathrm{C}$ and $2^{\circ} \mathrm{C}$ of global warming (a. $\mathrm{RCP} 4.5$ and $1.5^{\circ} \mathrm{C}$ of warming; b.

For $2^{\circ} \mathrm{C}$ of global warming, under RCP8.5 scenario, the distribution areas of the high, medium, and low risk zones would increase to different extents. The expansion of the medium risk zone would be most significant, and mainly affects the eastern part of Northwest China and the central and western parts of Southwest China. The medium-high risk zones would account for more than $48 \%$ of the national total land area in China. Under RCP4.5 scenario, the distribution areas of the high risk and medium risk zones would increase slightly, mainly in North China and the eastern part of Northwest China, while the distribution area of the low risk zones would decrease slightly. The medium-high risk zones would account for more than half of the national total land area in China (Fig. 7b, d).

\section{Discussion}

240 In the future, with the continuous intensification of global warming, the impact and distribution area of severe and moderate flood events with more serious impacts would continue to expand, and the social and economic risks of floods would become more serious. In terms of climate scenarios, the distribution area of floods under RCP4.5 scenario would be broader; however, under RCP8.5 scenario, the floods would affect more people, the direct economic losses would account for a larger proportion 
of the GDP, and the adverse impact on the social economy would be more serious. For the contribution of various components

to the floods risks, we take the severe floods in Northeast China (including Heilongjiang, Jilin, Liaoning and the eastern of Inner Mongolia) as an example to discuss. According to formula (3), for $1.5^{\circ} \mathrm{C}$ of global warming, the affected population (units: million) and the direct economic losses (units: US\$ billion) of severe floods in Northeast China would be $0.2880 \approx$ $30.73 \% \times 129.8462 \times 0.0130 \times 0.5552$ and $1.0518 \approx 11.83 \% \times 1231.8067 \times 0.0130 \times 0.5552$, respectively; for $2^{\circ} \mathrm{C}$ of global warming, the affected population and the direct economic losses would be $0.3622 \approx 30.73 \% \times 145.1178 \times 0.0144 \times 0.5640$ and $2.4842 \approx 11.83 \% \times 2585.6269 \times 0.0144 \times 0.5640$, respectively. Since the vulnerability and the environmental correction parameter would be basically unchanged, the increase of risk would mainly depend on the hazard and exposure. The contribution of hazard and exposure in population risk would be about the same, and the contribution of exposure in economic risk would be about twice of the hazard. By understanding floods and their impacts, it is urgent to clarify the required adaption to climate change and implement plans for the different possible situations in order to reduce disaster losses and ensure the sustainable development of the social economy (Jevrejeva et al., 2018; Jongman, 2018; Lim et al., 2018; Wu et al., 2018b).

Future intensification of global warming (IPCC, 2013) and the frequent occurrence of extreme meteorological and hydrological events (Rahmstorf and Coumou, 2011; Bao et al., 2017; Kendon, 2018) will have an important impact on the social economy, natural ecosystem, and food production (Piao et al., 2010; Bellard et al., 2012; Burke et al., 2015; Carleton and Hsiang, 2016; Lesk et al., 2016). The losses caused by floods are closely related to the socio-economic background. The exposure and vulnerability of risk bearing bodies will change in response to climate change, social and economic development, and disaster prevention and mitigation capabilities. Uncertainty of quantitative assessment for the social and economic risk of pluvial flood may arise in three components (i.e., probability or hazard, vulnerability and exposure). There are uncertainty in the simulation and downscaling of global climate models (GCMs). The use of Multi-model ensemble methods and the improvement of simulation accuracy are conducive to the reduction of uncertainty. The provincial scale of vulnerability of the affected population and the direct economic losses is insufficient to characterize spatial heterogeneity. Future research needs to continuously introduce the latest disaster data, modify the vulnerability curve, and improve the reliability of the vulnerability assessment (Huang et al., 2012; Ouma and Tateishi, 2014). Exposure data from SSPs is difficult to reflect the impact of climate change and climate policy, which will lead to systematic deviation in risk assessment. It is necessary to build high spatialtemporal resolution SSPs basic element data in combination with China's national conditions (Chen et al., 2020).

This paper examines the social and economic risks caused by precipitation-generated inland floods, but does not consider coastal floods caused by storm surges and sea level rise. The factors affecting the formation of inland floods also include the antecedent conditions of rivers and their drainage basins, the properties and status of the soil, the vegetation cover, and urbanization. This paper mainly focuses on large-scale flood disasters at the national level. The influence of the antecedent conditions of rivers and their drainage basins is reflected in the altitude and slope. Factors such as soil, vegetation, and urbanization mainly affect the formation of small-scale floods (Blöschl et al., 2007). Therefore, the environmental correction parameter for the underlying surface does not consider the above factors. Of course, when studying small-scale or regional 
flood disasters, the above factors should be considered according to the actual situation (Kron, 2005; Bates et al., 2008; Kundzewicz et al., 2014).

\section{Conclusions}

280 Based on future scenario data, in this paper, we calculated the hazard of floods under global warming of $1.5^{\circ} \mathrm{C}$ and $2^{\circ} \mathrm{C}$ and quantitatively assessed the social and economic risks of floods, and drawn the following conclusions.

(1) In the future, the hazard and impact range of floods of different levels in China would increase, and the area affected by severe floods would expand the fastest. For $2^{\circ} \mathrm{C}$ of global warming, severe floods would cover more than 2 million km 2 under RCP4.5 and RCP8.5 scenarios.

285 (2) Flood disasters seriously affect social and economic development in China. The population and the direct economic loss affected by floods would continue to increase under different climatic and socioeconomic scenarios with increasing global warming. Compared to $1.5^{\circ} \mathrm{C}$ of global warming, for $2^{\circ} \mathrm{C}$ of global warming, the affected population of severe floods would increase by about 2 million under RCP8.5 scenario and decrease slightly under RCP4.5 scenario; the economic risk would double under RCP8.5 scenario and triple under RCP4.5 scenario, but the proportion of the GDP would be less than that for RCP8.5 scenario.

(3) The regions with medium-high integrated risks would be mainly distributed in Northeast China, North China, East China, Central China, and South China. With increasing climate change and socioeconomic development, the range of the mediumhigh flood risk zones gradually expands westward and northward. For $2^{\circ} \mathrm{C}$ of global warming, the area of the medium-high risk zones would account for about half of the national total land area in China.

\section{Acknowledgments}

This research was supported by the National Key R\&D Program of China (2018YFC1508801, 2018YFC1509002), the "Strategic Priority Research Program" of the Chinese Academy of Sciences (Grant No. XDA19040304), the National Natural Science Foundation of China (Grant No. 41530749).

\section{References}

300 Alfieri, L., Feyen, L., Dottori, F., and Bianchi, A.: Ensemble flood risk assessment in Europe under high end climate scenarios, Global. Environ. Chang, 35, 199-212, https://doi.org/10.1016/j.gloenvcha.2015.09.004, 2015.

Bao, J., Sherwood, S. C., Alexander, L. V., and Evans, J. P.: Future increases in extreme precipitation exceed observed scaling rates, Nat. Clim. Change, 7, 128-132, https://doi.org/10.1038/nclimate3201, 2017. 
Bates, B., Kundzewicz, Z., Wu, S., and Palutikof, J.: Climate Change and Water, Technical Paper of the Intergovernmental Panel on Climate Change, pp37-38, 2008.

Bellard, C., Bertelsmeier, C., Leadley, P., Thuiller, W., and Courchamp, F.: Impacts of climate change on the future of biodiversity, Ecol. Lett, 15, 365-377, https://doi.org/10.1111/j.1461-0248.2011.01736.x, 2012.

Bloeschl, G., Ardoin-Bardin, S., Bonell, M., Dorninger, M., Goodrich, D., Gutknecht, D., Matamoros, D., Merz, B., Shand, P., and Szolgay, J.: At what scales do climate variability and land cover change impact on flooding and low flows?, Hydrol. Process, 21, 1241-1247, https://doi.org/10.1002/hyp.6669, 2007.

Burke, M., Hsiang, S. M., and Miguel, E.: Global non-linear effect of temperature on economic production, Nature, 527, 235, https://doi.org/10.1038/nature15725, 2015.

Carleton, T. A. and Hsiang, S. M.: Social and economic impacts of climate, Science, 353, https://doi.org/10.1126/science.aad9837, 2016.

Chen, Y., Guo, F., Wang, J., Cai, W., Wang, C., and Wang, K.: Provincial and gridded population projection for China under shared socioeconomic pathways from 2010 to 2100, Scientific Data, 7, https://doi.org/10.1038/s41597-020-0421-y, 2020.

Ding, Y., Ren, G., Shi, G., and Gong, P.: National assessment report of climate change (I): climate change in China and its future trend, Advances in Climate Change Research, 2, 3-8, 2006.

Feng, A., Zeng, H., Yin, Y., Song, Y., Liu, Y., Wang, Y., Wang, L., Wang, Y., Zhu, X., Cai, W., Hou, W., Huang, D., Guo, Y., Zhang, Y., Zhong, H., Li, Y., Shi, S., Zhi, R., Hong, J., and Wang, D.: Climatic Characteristics and Major Meteorological Events over China in 2017, Meteorological Monthly, 44, 548-555, https://doi.org/10.7519/j.issn.10000526.2018.04.008, 2018.

Gao, J., Liu, L., and Wu, S.: Hazards of extreme events in China under different global warming targets, Big Earth Data, 4, 153-174, https://doi.org/10.1080/20964471.2020.1769254, 2020.

Gong, D. Y. and Wang, S. W.: Severe summer rainfall in China associated with enhanced global warming, Clim. Res, 16, 5159, https://doi.org/10.3354/cr016051, 2000.

Held, I. M. and Soden, B. J.: Robust responses of the hydrological cycle to global warming, J. Climate, 19, 5686-5699, https://doi.org/10.1175/jcli3990.1, 2006.

Hempel, S., Frieler, K., Warszawski, L., Schewe, J., and Piontek, F.: A trend-preserving bias correction - the ISI-MIP approach, Earth. Syst. Dynam, 4, 219-236, https://doi.org/10.5194/esd-4-219-2013, 2013.

Hirabayashi, Y., Mahendran, R., Koirala, S., Konoshima, L., Yamazaki, D., Watanabe, S., Kim, H., and Kanae, S.: Global flood risk under climate change, Nat. Clim. Change, 3, 816-821, https://doi.org/10.1038/nclimate1911, 2013.

Huang, D., Zhang, R., Huo, Z., Mao, F., Youhao, E., and Zheng, W.: An assessment of multidimensional flood vulnerability at the provincial scale in China based on the DEA method, Nat. Hazards, 64, 1575-1586, https://doi.org/10.1007/s11069012-0323-1, 2012.

Huang, J., Yu, H., Dai, A., Wei, Y., and Kang, L.: Drylands face potential threat under 2 degrees C global warming target, Nat. Clim. Change, 7, 417-422, https://doi.org/10.1038/nclimate3275, 2017. 
Huang, R., Chen, J., and Huang, G.: Characteristic's and variations of the East Asian monsoon system and its impacts on climate disasters in China, Adv. Atmos. Sci, 24, 993-1023, https://doi.org/10.1007/s00376-007-0993-x, 2007.

Huntington, T. G.: Evidence for intensification of the global water cycle: Review and synthesis, J. Hydrol, 319, 83-95, https://doi.org/10.1016/j.jhydrol.2005.07.003, 2006.

IPCC: Managing the risks of extreme events and disasters to advance climate change adaptation: special report of the intergovernmental panel on climate change, Cambridge University Press, UK, 2012.

IPCC: Climate change 2013: the physical science basis: Working Group I contribution to the Fifth assessment report of the Intergovernmental Panel on Climate Change, Cambridge University Press, UK, 2013.

IPCC: Climate change 2014-Impacts, adaptation and vulnerability, Cambridge University Press, UK, 2014.

IPCC: Global warming of 1.5 C An IPCC Special Report on the impacts of global warming of 1.5 C above pre-industrial levels and related global greenhouse gas emission pathways, in the context of strengthening the global response to the threat of climate change, sustainable development, and efforts to eradicate poverty, Cambridge University Press, UK, 2018.

Jevrejeva, S., Jackson, L. P., Grinsted, A., Lincke, D., and Marzeion, B.: Flood damage costs under the sea level rise with warming of 1.5 degrees C and 2 degrees C, Environ. Res. Lett, 13, https://doi.org/10.1088/1748-9326/aacc76, 2018.

Johnson, F., White, C. J., van Dijk, A., Ekstrom, M., Evans, J. P., Jakob, D., Kiem, A. S., Leonard, M., Rouillard, A., and Westra, S.: Natural hazards in Australia: floods, Climatic Change, 139, 21-35, https://doi.org/10.1007/s10584-016-1689y, 2016.

Jones, P. D. and Hulme, M.: Calculating regional climatic time series for temperature and precipitation: Methods and illustrations, Int. J. Climatol, 16, 361-377, https://doi.org/10.1002/(sici)1097-0088(199604)16:4<361::aidjoc53>3.0.co;2-f, 1996.

Jongman, B.: Effective adaptation to rising flood risk COMMENT, Nat. Commun, 9, https://doi.org/10.1038/s41467-01804396-1, 2018.

Karmalkar, A. V. and Bradley, R. S.: Consequences of Global Warming of 1.5 degrees C and 2 degrees C for Regional Temperature and Precipitation Changes in the Contiguous United States, Plos One, 12, https://doi.org/10.1371/journal.pone.0168697, 2017.

Kharin, V. V., Flato, G. M., Zhang, X., Gillett, N. P., Zwiers, F., and Anderson, K. J.: Risks from Climate Extremes Change Differently from 1.5 degrees C to 2.0 degrees C Depending on Rarity, Earths Future, 6, 704-715, https://doi.org/10.1002/2018ef000813, 2018.

King, A. D. and Karoly, D. J.: Climate extremes in Europe at 1.5 and 2 degrees of global warming, Environ. Res. Lett, 12, https://doi.org/10.1088/1748-9326/aa8e2c, 2017a.

King, A. D., Karoly, D. J., and Henley, B. J.: Australian climate extremes at 1.5 degrees C and 2 degrees C of global warming, Nat. Clim. Change, 7, 412-416, https://doi.org/10.1038/nclimate3296, 2017 b.

370 Kron, W.: Flood risk = hazard center dot values center dot vulnerability, Water. Int, 30, 58-68, https://doi.org/10.1080/02508060508691837, 2005. 
Kundzewicz, Z. W., Kanae, S., Seneviratne, S. I., Handmer, J., Nicholls, N., Peduzzi, P., Mechler, R., Bouwer, L. M., Arnell, N., Mach, K., Muir-Wood, R., Brakenridge, G. R., Kron, W., Benito, G., Honda, Y., Takahashi, K., and Sherstyukov, B.: Flood risk and climate change: global and regional perspectives, Hydrolog. Sci. J, 59, 1-28, https://doi.org/10.1080/02626667.2013.857411, 2014.

Lesk, C., Rowhani, P., and Ramankutty, N.: Influence of extreme weather disasters on global crop production, Nature, 529, 84-87, https://doi.org/10.1038/nature16467, 2016.

Li, K., Wu, S., Dai, E., and Xu, Z.: Flood loss analysis and quantitative risk assessment in China, Nat. Hazards, 63, 737-760, https://doi.org/10.1007/s11069-012-0180-y, 2012.

Li, R., Li, Y., and Xu, Y.: Projection of Rainstorm and Flooding Disaster Risk in China in the 21st Century, Journal of Arid Meteorology, 36, 341-352, https://doi.org/10.11755/j.issn.1006-7639(2018)-03-0341, 2018a.

Li, W., Jiang, Z., Zhang, X., Li, L., and Sun, Y.: Additional risk in extreme precipitation in China from 1.5 degrees $\mathrm{C}$ to 2.0 degrees C global warming levels, Sci. Bull, 63, 228-234, https://doi.org/10.1016/j.scib.2017.12.021, 2018b.

Lim, W. H., Yamazaki, D., Koirala, S., Hirabayashi, Y., Kanae, S., Dadson, S. J., Hall, J. W., and Sun, F.: Long-Term Changes in Global Socioeconomic Benefits of Flood Defenses and Residual Risk Based on CMIP5 Climate Models, Earths Future, 6, 938-954, https://doi.org/10.1002/2017ef000671, 2018.

Lin, L., Wang, Z., Xu, Y., Zhang, X., Zhang, H., and Dong, W.: Additional Intensification of Seasonal Heat and Flooding Extreme Over China in a 2 degrees C Warmer World Compared to 1.5 degrees C, Earths Future, 6, 968-978, https://doi.org/10.1029/2018ef000862, 2018.

Luo, P., Mu, D., Xue, H., Thanh, N.-D., Kha, D.-D., Takara, K., Nover, D., and Schladow, G.: Flood inundation assessment for the Hanoi Central Area, Vietnam under historical and extreme rainfall conditions, Sci. Rep-Uk, 8, https://doi.org/10.1038/s41598-018-30024-5, 2018.

Ma, M., He, B., Wan, J., Jia, P., Guo, X., Gao, L., Maguire, L. W., and Hong, Y.: Characterizing the Flash Flooding Risks from 2011 to 2016 over China, Water, 10, https://doi.org/10.3390/w10060704, 2018.

Murakami, D. and Yamagata, Y.: Estimation of Gridded Population and GDP Scenarios with Spatially Explicit Statistical Downscaling, Sustainability, 11, https://doi.org/10.3390/su11072106, 2019.

Nikulin, G., Lennard, C., Dosio, A., Kjellstrom, E., Chen, Y., Haensler, A., Kupiainen, M., Laprise, R., Mariotti, L., Maule, C. F., van Meijgaard, E., Panitz, H.-J., Scinocca, J. F., and Somot, S.: The effects of 1.5 and 2 degrees of global warming on Africa in the CORDEX ensemble, Environ. Res. Lett, 13, https://doi.org/10.1088/1748-9326/aab1b1, 2018.

O'Neill, B. C., Kriegler, E., Riahi, K., Ebi, K. L., Hallegatte, S., Carter, T. R., Mathur, R., and van Vuuren, D. P.: A new scenario framework for climate change research: the concept of shared socioeconomic pathways, Climatic Change, 122, 387-400, https://doi.org/10.1007/s10584-013-0905-2, 2014.

Ouma, Y. O. and Tateishi, R.: Urban Flood Vulnerability and Risk Mapping Using Integrated Multi-Parametric AHP and GIS: Methodological Overview and Case Study Assessment, Water, 6, 1515-1545, https://doi.org/10.3390/w6061515, 2014. 
https://doi.org/10.5194/nhess-2021-304

Preprint. Discussion started: 21 October 2021

(c) Author(s) 2021. CC BY 4.0 License.

Papathoma-Koehle, M., Schloegl, M., and Fuchs, S.: Vulnerability indicators for natural hazards: an innovative selection and weighting approach, Sci. Rep-Uk, 9, https://doi.org/10.1038/s41598-019-50257-2, 2019.

Paprotny, D., Sebastian, A., Morales-Napoles, O., and Jonkman, S. N.: Trends in flood losses in Europe over the past 150 years, Nat. Commun, 9, https://doi.org/10.1038/s41467-018-04253-1, 2018.

Parmesan, C. and Yohe, G.: A globally coherent fingerprint of climate change impacts across natural systems, Nature, 421, 37-42, https://doi.org/10.1038/nature01286, 2003.

Patz, J. A., Campbell-Lendrum, D., Holloway, T., and Foley, J. A.: Impact of regional climate change on human health, Nature, 438, 310-317, https://doi.org/10.1038/nature04188, 2005.

Piao, S., Ciais, P., Huang, Y., Shen, Z., Peng, S., Li, J., Zhou, L., Liu, H., Ma, Y., Ding, Y., Friedlingstein, P., Liu, C., Tan, K., Yu, Y., Zhang, T., and Fang, J.: The impacts of climate change on water resources and agriculture in China, Nature, 467, 43-51, https://doi.org/10.1038/nature09364, 2010.

Rahmstorf, S.: Rising hazard of storm-surge flooding, P. Natl. Acad. Sci. USA, 114, 11806-11808, https://doi.org/10.1073/pnas.1715895114, 2017.

Rahmstorf, S. and Coumou, D.: Increase of extreme events in a warming world, P. Natl. Acad. Sci. USA, 108, 17905-17909, https://doi.org/10.1073/pnas.1101766108, 2011.

420 Song L: China meteorological disaster yearbook 2016: Beijing, China, China Meteorological Press, China, 2016.

Su, B., Huang, J., Fischer, T., Wang, Y., Kundzewicz, Z. W., Zhai, J., Sun, H., Wang, A., Zeng, X., Wang, G., Tao, H., Gemmer, M., Li, X., and Jiang, T.: Drought losses in China might double between the 1.5 degrees $\mathrm{C}$ and 2.0 degrees $\mathrm{C}$ warming, P. Natl. Acad. Sci. USA, 115, 10600-10605, https://doi.org/10.1073/pnas.1802129115, 2018.

Swiss Re Group: https://www.swissre.com/media/news-releases/2017/nr20171220_sigma_estimates.html. , last access: 8 October 2021.

Thompson, A. and Clayton, J.: The role of geomorphology in flood risk assessment, P. I. Civil. Eng-Civ. En, 150, 25-29, https://doi.org/10.1680/cien.2002.150.5.25, 2002.

Trenberth, K. E., Dai, A., van der Schrier, G., Jones, P. D., Barichivich, J., Briffa, K. R., and Sheffield, J.: Global warming and changes in drought, Nat. Clim. Change, 4, 17-22, https://doi.org/10.1038/nclimate2067, 2014.

UNFCCC: https://unfccc.int/sites/default/files/english_paris_agreement.pdf., last access: 8 October 2021.

UNISDR, CRED: https://www.unisdr.org/files/61119_credeconomiclosses.pdf., last access: 8 October 2021.

Wahl, T., Jain, S., Bender, J., Meyers, S. D., and Luther, M. E.: Increasing risk of compound flooding from storm surge and rainfall for major US cities, Nat. Clim. Change, 5, 1093-1097, https://doi.org/10.1038/nclimate2736, 2015.

Warszawski, L., Frieler, K., Huber, V., Piontek, F., Serdeczny, O., and Schewe, J.: The Inter-Sectoral Impact Model Intercomparison Project (ISI-MIP): Project framework, P. Natl. Acad. Sci. USA, 111, 3228-3232, https://doi.org/10.1073/pnas.1312330110, 2014.

Weedon, G. P., Gomes, S., Viterbo, P., Shuttleworth, W. J., Blyth, E., Oesterle, H., Adam, J. C., Bellouin, N., Boucher, O., and Best, M.: Creation of the WATCH Forcing Data and Its Use to Assess Global and Regional Reference Crop 
Evaporation over Land during the Twentieth Century, J. Hydrometeorol, 12, 823-848, https://doi.org/10.1175/2011jhm1369.1, 2011.

Willner, S. N., Otto, C., and Levermann, A.: Global economic response to river floods, Nat. Clim. Change, 8, 594-598, https://doi.org/10.1038/s41558-018-0173-2, 2018.

Witze, A.: Why extreme rains are gaining strength as the climate warms, Nature, 563, 458-460, https://doi.org/10.1038/d41586-018-07447-1, 2018.

445 Wobus, C., Gutmann, E., Jones, R., Rissing, M., Mizukami, N., Lorie, M., Mahoney, H., Wood, A. W., Mills, D., and Martinich, J.: Climate change impacts on flood risk and asset damages within mapped 100-year floodplains of the contiguous United States, Nat. Hazard. Earth. Sys, 17, 2199-2211, https://doi.org/10.5194/nhess-17-2199-2017, 2017.

Writing Committee for Third National Assessment Report on Climate Change: Third National Assessment Report on Climate Change: Beijing, China: Science Press, China, 2015.

450 Wu, S., Gao, J., Deng, H., Liu, L., and Pan, T.: Climate change risk and methodology for its quantitative assessment, Progress in Geography, 37, 28-35, https://doi.org/10.18306/dlkxjz.2018.01.004, 2018a.

Wu, S., Pan, T., Liu, Y., Gao, J., and He, X.: Orderly adaptation to climate change: A roadmap for the post-Paris Agreement Era, Sci. China. Earth. Sci, 61, 119-122, https://doi.org/10.1007/s11430-016-9113-x, 2018b.

Xu, Y., Zhang, B., Zhou, B.-T., Dong, S.-Y., Yu, L., and Li, R.-K.: Projected Flood Risks in China Based on CMIP5, Advances in Climate Change Research, 5, 57-65, https://doi.org/10.3724/sp.j.1248.2014.057, 2014.

Zhai, P. M., Zhang, X. B., Wan, H., and Pan, X. H.: Trends in total precipitation and frequency of daily precipitation extremes over China, J. Climate, 18, 1096-1108, https://doi.org/10.1175/jcli-3318.1, 2005.

Zhai, P. M., Sun, A. J., Ren, F. M., Liu, X. N., Gao, B., and Zhang, Q.: Changes of climate extremes in China, Climatic Change, 42, 203-218, https://doi.org/10.1023/a:1005428602279, 1999.

Zhang, W., Zhou, T., Zou, L., Zhang, L., and Chen, X.: Reduced exposure to extreme precipitation from 0.5 degrees C less warming in global land monsoon regions, Nat. Commun, 9, https://doi.org/10.1038/s41467-018-05633-3, 2018.

Zhou, C., Wan, Q., Huang, S., and Chen, D.: A GIS-based Approach to Flood Risk Zonation, Acta Geographica Sinica, 1524, 2000. 